\title{
Obstacles to Progress in R\&D Activities Caused by Institutional and Regulatory Frameworks: The Case of the Biotech Sector in Colombia
}

\author{
Fabio F. Moscoso D. ${ }^{1}$, Fernando Estrada ${ }^{2}$, Natalia Diaz R. ${ }^{2}$ \& Nelson A. Andrade V. ${ }^{1}$ \\ ${ }^{1}$ School of Management - Postgraduate studies, EAN University, Bogotá, Colombia \\ ${ }^{2}$ School of Economics, Industrial University of Santander, Bucaramanga, Colombia \\ Correspondence: Fabio F. Moscoso D., School of Management - Postgraduate studies, Universidad EAN, Bogotá, \\ Carrera $11 \mathrm{~N}^{\circ}$ 78-47, Colombia. Tel: 57-1-593-6464 ext. 2160.
}

Received: November 17, 2015

Accepted: November 30, 2015

Online Published: December 20, 2015

doi:10.5430/rwe.v6n4p116

URL: http://dx.doi.org/10.5430/rwe.v6n4p116

\begin{abstract}
This article is based on an exhaustive review of empirical evidence from secondary sources of information seeking to answer the research question: What are the main obstacles raised by the Institutional and Regulatory framework for R\&D activities in Colombia's biotechnology sector?

The main findings indicate: (I) that there is a flawed competitive environment that tends to create oligopolies and other scenarios that facilitate the hoarding of information and knowledge and prevent access by many scientists to relevant new information breakthroughs, thus generating material asymmetries between the scientific communities of developed and developing countries; and (II) that other obstacles, generally associated with government shortcomings, produce non-financial transaction costs in terms of time and administrative processes, that represent significant impediments to the development of the biotechnology industry and which, in the Colombian case, have slowed progress in the sector.
\end{abstract}

Keywords: biotechnology, property rights, public policy, institutional environment

\section{Background}

There is an important aspect that highlights the relevance of this investigation: Questions related to progress and technological innovation occupy an essential place on governmental agendas. Despite the efforts to advance in this subject, there are elements from the institutional and regulatory environment that neutralize any determination from the economic policy, and impede that improvements in the biotechnology sector permeate the society to improve its well-being and quality of life. Regardless of the importance of the subject, there is a large knowledge gap, both in number of researches in the topic as in the scenarios that such studies have been applied, like the case of Latin America, and more specifically in the Colombian case, that impede to establish its findings as facilitators for future relations between public policy, the government and the private sector, to improve the developments in biotechnology.

In recent years the biotechnology industry has experienced significant rates of technological development and created a range of new applications, with an increase in the production of high value-added pharmaceuticals, cosmetics and chemicals. Increased competition between biotechnology companies has become more noticeable and there is a tendency to develop clearer strategic lines of action in order to survive and grow in a market characterized by asymmetric competitive forces. Some studies suggest a decline in market barriers for biotech products despite the persistence of other types of deterrents in the industry (OECD - Festel Capital, 2010).

A major market failure identified in this industry is a tendency towards the formation of oligopolies and other scenarios characterized by imperfect competition. The industry's market structure comprises three different types of organizations: (I) small start-ups; (II) medium-sized companies; and (III) major multinationals. Their operations can be highly specialized, creating only a small portion of the total value added along the production chain, or their production can be diversified (OECD - Festel Capital, 2010). In this regard, there is certain concern about the effect of management on the protection of intellectual property, which "can help strengthen monopolies, and eventually exclude small businesses from the market, especially in developing countries" (Defrancesco, E. and Runge F., 2006). 
It is known, for example, that in 1995 alone, European and U.S. companies invested USD 3.5 billion in acquiring smaller biotech companies (Pinilla E., 2004).

Nowadays, as noted by Juma, C. and Honca, D. (2002), the market is the domain of the private sector multinationals in the US and Europe, despite the participation of other countries which, notwithstanding the presence of a large number of small businesses whose number easily exceeds that of the multinational companies, hold a minor market share in a scenario where multinationals represent an oligopolistic structure and command the largest proportion of worldwide sales, according to market share data.

In the Colombian case, according to information obtained from Colciencias (2008), local companies dominate the market with a $73 \%$ share. However, the majority of these companies are small in size, with almost $50 \%$ of them having less than 50 employees. These are followed by $28 \%$ that are defined as medium-sized. Only 30 laboratories ( $22 \%$ of the country's total) have more than 200 employees, and these generate $73 \%$ of the sector's jobs and contribute $83 \%$ of total production. It is the multinationals who actually control the market.

One of the negative consequences of the majority presence of multinationals in the Colombian market is associated with their modus operandi. In general, these businesses only import processed products that are locally packaged for sale to the Colombian market. Only one of the multinational laboratories has a production plant in the country, the rest import all their products ready-made by their parent companies or plants located in other countries. This situation goes beyond a simple appropriation of the market; it creates an environment that prevents the generation of spillover effects, particularly in terms of knowledge and technology transfer, that discourage the development of the domestic biotechnology industry.

Patents, while being a key incentive to investment in innovation, are also a source of monopoly power (Pearse, N., 2007). In general, monopolies of information and know-how, in the form of patents, deprive many researchers of access to relevant information that will further scientific advances (Defrancesco, E. and Runge F., 2006). This situation is prone to generate strong asymmetries of information between the scientific communities of developed and developing countries.

One sector that aptly reflects such a monopolistic situation is the Colombian seed market, where four multinationals (Dupont, Sygenta, Monsanto and Bayer Cropscience) clearly dominate the market, followed by 3 local companies (Semillas la Pradera, Semillas Andree and Procampo S.A.) (Colciencias, 2008). It is further suggested that the management of intellectual property rights has favored the creation of monopolies and in certain cases that patent management has stimulated the concentration of developments in different fields (Pinilla E., 2004). In any event, there is a strategic behavior common to large companies whereby they seek to concentrate knowledge, capital, technology and patents. Experts also comment that the struggle for patents is essentially unfair (Pinilla E., 2004).

In Latin America, the main obstacles to progress in countries such as Argentina, Brazil and Colombia are associated with government and market shortcomings arising from:

1) The scarcity of resources, despite public funds being available that are specifically intended to promote scientific and technological research in fields covered by biotechnology. This circumstance generates extra costs in terms of time and administrative processes, that make it more difficult to obtain financing that is suited to the specific industry and its business environment. For instance, in 2012, Colombia spent $0.449 \%$ of its GDP on scientific and technological activities and $0.17 \%$ on research and development (Colombian Observatory for Science and Technology - OC\&T - 2012), significantly less than the target of 1\%. In 2013, Colciencias (Colombia's Administrative Department of Science, Technology and Innovation) suffered a major institutional crisis due to significant funding cuts.

2) Difficulties in increasing investments in infrastructure and applied research, and other financial constraints (Zylberberg, C. et al., 2012);

3) Lack of coordination between academia, the private sector and the government aimed at channeling research activities towards strategic areas and focusing research on satisfying market needs. Asymmetric information from these agents has hampered the arrival of new forms of private local and foreign capital.

4) Excessive costs in terms of administrative red tape for importing a wide variety of biotechnological inputs and difficulties in marketing scientific discoveries.

5) A regulatory framework that hinders investigation, including laws and procedures in sectors such as pharmaceuticals, herbal medicine, nutraceuticals, cosmetics and personal care that generate administrative costs in terms of time (Colciencias, 2008) 
6) Shortage of partnerships between local actors and outsiders, (despite the initiatives promoted by the Colombian government and, in the case of Argentina and Brazil, MERCOSUR cooperation agreements), which can be associated with: lack of coordination, procurement information and highly specialized expertise; uncertain quality of the partner and its contributions; the need to monitor the performance of distribution areas; control over the proper handling of highly specialized information; foreseeing contingencies in contracts; the possibility of opportunistic behavior in the interaction of cooperating agents with notable asymmetries of power between them, among others.

7) In many cases, the absence of a specialized body in multidisciplinary areas that mitigates coordination problems and asymmetric information and that expedites cumbersome procedures for research centers and biotechnology companies.

Generally speaking, these situations denote coordination failures and serve to increase investors' uncertainty and perception of risk. (González, C. et al., 2007).

Apart from the foregoing, the biotech industry faces many major challenges and obstacles to its development, associated with:

1) Acceptance by consumers of products with potential impacts on human health, the environment and economic dynamics. This necessarily implies compliance with biosafety regulations that may occasionally act as market barriers, but which in turn are recognized more by large biotech companies as being critical to their avoiding negative actions being brought or taken against them, to maintaining political support of the industry and ensuring the sustainability of their businesses.

2) Acceptance of biosecurity, sustainability and other principles established in biosecurity protocols in the industry (such as the case for Colombia of the Cartagena Protocol), based on conservation, preservation and reduction in the risk of disease in the biodiversity, are of fundamental importance in countries with similar biodiversity characteristics.

3) Technical risks inherent to the biotechnology industry, due to the complexity of the underlying activities.

4) Regulation. Biotechnology is one of the most highly-regulated industries in the world and its development is subject to numerous rules and procedures for achieving marketing approval, which may also change over time, creating uncertainty regarding regulatory processes.

5) Financial. Biotechnology is highly capital intensive and companies in this sector depend heavily on their ability to access capital funding in order to develop their products.

\section{The Institutional Framework Applied to the Biotechnology Market in Colombia}

Companies' potential for development depends largely on the institutional environment within which they operate. This is because of the administrative procedures, legal requirements, need to find sources of financing and the coordination of a large number of agents, among other aspects, that are required to reach the commercialization stage. In this sense, the institutions of control established in the market where the company is located can exert a powerful influence.

Today the government of Colombia recognizes the strategic importance of biotechnology as a future engine of economic growth for the country (Castellanos, O. et al., 2011). Consistent with this goal, it has sought to develop different institutional mechanisms to foster growth in the sector. The relevance of public policy in biotechnology has also been highlighted in national policy documents whose purpose is to generally improve the technical, economic and institutional conditions for the development of the sector (Foros Semana, 2011).

The objectives of such policies contemplate: (i) creating the legal, economic, technical and institutional conditions for attracting public and private resources towards the business development of products based on the country's immeasurable biodiversity; (ii) improving the institutional capacity required for the commercial development of biotechnology; (iii) developing a set of economic instruments to attract public investment in the development of companies and biotech products; (iv) adapting and reviewing the regulatory framework related to the access to genetic resources, production and marketing of biotech medications and herbal products; and (v) evaluating the creation of the National Bioprospecting Enterprise.

In this regard, feasibility studies have been undertaken for the creation of the National Bioprospecting Enterprise and plans are afoot for the creation of an inter-sectoral committee that will report to the different government entities whose authorization is required for the development of biotechnology. Two national centers are also proposed: (i) the National Center for Genomics, the country's administrative body for collecting genetic information and massive 
parallel DNA sequencing; (ii) the Center for Bioinformatics and Computational Biology in Manizales, which processes the information collected by the first named (Foros Semana, 2011). The Business Development and Foreign Trade Bank of Colombia (Bancóldex) is involved in the management of seed capital generated through royalties.

The declared intention of the institutional framework developed by the Colombian government is that the establishment environment should be conducive to public and private national research centers and access to new technologies and strategic alliances, in conjunction with international cooperation projects, bringing together academics and domestic and foreign business and financial agents, with a view to achieving an overall integration of the market, thanks to the joint participation of the public and private sectors (Colciencias, 2008).

However, the real-life scenario shows signs of inconsistencies between the rhetoric and reality, which has resulted in quite modest achievements in R\&D (González, J., 2011). For instance, there have been significant cutbacks in Colciencias budgetary resources in recent years, and this has generated a dynamic dispute among the regions regarding the General System of Royalties, largely due to the government's insistence that Colciencias define priorities, which, per se, is incompatible with the agency's stated mission. Furthermore, it is feared that the resources will be lost if they are destined to local projects, and will end up having no impact on the consolidation of R\&D.

Empirical cases demonstrate the complexity of the procedure as well as the difficulties involved in appropriately informing those interested in biotechnological developments. The absence of an institutional environment, whose structure could take the form of offices acting as administrative units and links, is sorely noted. Excessive red tape; lack of clarity as to the procedural requirements; excessive lead times for compliance with each of the stages; uncertainty as to the total time required for the completion of all the processes involved; processing delays caused by entities directly or indirectly related to the procedure; additional requirements not established in the prerequisites and / or lead times that do not correspond to those specified, among others, are just some of the most important circumstances generating extra / unplanned transaction costs in terms of time and money that most affect the smaller companies (MSMEs), which are a majority in Colombia, to the extent that they lack the human and financial resources needed to deal with all of them. These difficulties therefore encourage imperfect competition since the MSMEs are essentially subject to the same procedures as the multinationals, whose power in terms of resources is obviously far greater.

According to the study conducted by Innpulsa Colombia, (2013), other limitations along the production chain of technology-related goods and services in Colombia are evident, namely:

1) Lack of coordination among key agents in the development of this industry, resulting from an absence of the institutions and entities that should be performing this function.

2) Difficulties in amending the existing legislation which hinders research and development in this area. For instance, it has not been possible to establish a general framework, therefore obliging the researcher to apply for individual permits for each active ingredient, with a consequent proliferation of bureaucratic costs, waste of time and investor uncertainty.

3) Paperwork, bureaucratic costs and time losses involved in accessing existing, but insufficient, funding sources.

4) Multiple difficulties in achieving compliance with agreements, and even legal barriers against meeting the political commitments made by the National Council on Economic and Social Policy in CONPES 3697 of 2011 (Policy for the Commercial Development of Biotechnology through the Sustainable Use of the Biodiversity)..

5) Lack of coordination and sharing of information among institutional agents due to the absence of suitable incentives, collectively preventing full usage of the capital (human, technological and knowledge) available in the universities to meet the needs of the sector. The universities also lack the guidelines needed to assess the knowledge and technology they develop.

6) Complex bureaucratic processes that have to be overcome to access biobanks.

7) Problems of uncertainty and risk. As an example, the Common Provisions on Industrial Property applicable in Colombia (governed by Andean Community Decision 486), significantly limit the scope of protection of potential intellectual property. Furthermore, the regulations on the distribution of royalties create a loophole in the designation of who actually owns the industrial property rights generated with these resources. 
8) Problems of asymmetric information and uncertainty regarding the potential negative effects of biotechnology developments that have contributed to "the poor image of the biotechnology sector and social rejection due to their association with excessive genetic manipulation".

9) Imperfect information leading to: difficulties in identifying suitable partners in academia; time costs resulting from slow procurement under Law 80 of 1993 (issuing the general rules for public procurement), which hinders access by innovative Colombian MSMEs to public contracts.

10) Higher administrative costs in export processes due to controls imposed by the National Institute for Food and Drug Monitoring (INVIMA) - and on entities not certified by the International Laboratory Accreditation Collaboration (ILAC), among others.

The following are among the factors influencing the scarcity of resources: investors' strong aversion to risk; the opportunity costs of investing in real estate and difficulties in accessing public resources arising from the "precarious flexibility of convocations in areas such as the type and size of bankable projects, deadlines (open window)". Similarly, it should be noted that not all sources of funding, whether they are public or private, will work or be readily available for all stages of the projects (research, development, marketing, etc.). The researcher and / or entrepreneur must know which type of funding source best suits the particular stage of the project.

Research conducted by Innpulsa Colombia (2013; p.111) into the potential of the country's biotechnology has found that the fiscal incentives available for research and development are not consistent with the characteristics of biotechnology projects, which have negative cash flows over a number of years; moreover, the complexity of access to them makes them unattractive to MSMEs. $80 \%$ of the companies questioned believe that public funding is inadequate and fails to meet the needs of this sector. It is also slow, and plagued with unnecessary red tape (p.81). On the demand side, an overwhelming majority of companies stated that the main limitations to incorporating biotechnological solutions in their products, apart from funding, are ignorance as to the possible choices available, shortage of specialized suppliers and a lack of qualified personnel (p.94). Companies requiring specific information for moving ahead with the development of new processes, based on research protected by patents granted in the US, (considered the largest scientific bioprospecting market in the world), face other sets of difficulties.

Research has also found that institutions such as the Francisco José de Caldas Fund (a financing arm of Colciencias) operate very slowly meaning that prompt and simple access to funding is impossible, making the process unattractive for many small- and medium-sized firms. Similarly, access to the resources of the general royalty system is very restricted due to the subordination of project structuring to the general adjusted methodology, and to the determination of the Collegiate Decision-Making Authority (OCAD), taken according to regional impact criteria, among others.

\section{Strategies Implemented to Achieve Progress in the Biotechnology Sector}

Upon reviewing the business strategies employed to promote the development of the biotechnology sector, it was found that each country develops its own differentiated strategy, but there are nevertheless common elements according to market conditions, obstacles and potentials of the country. Many are intended to improve coordination between national and international actors working on joint projects and encourage strategies that mitigate the obstacles caused by the problems described above.

Biotech companies in India have sought ways to establish partnerships with multinational corporations, with a view to enhancing the credibility of small businesses and increasing the chances of forming potential partnerships. Through service contracts and partnerships with large companies, organizations and laboratories in other countries some of these companies conduct clinical trials or perform very specific production processes within a longer production chain, or develop joint-venture projects. Others choose to become subsidiaries of companies with greater technological and financial capacity, not only to access new financial resources but also technology, experience and know-how, at the same time achieving access to markets in other countries (Frew, S. et al., 2007). It is claimed that these strategies not only allow small businesses to access technology, knowledge and valuable experience, they also reduce the risk involved in major investments and increase the chance of obtaining approval from care research centers in developing countries. Through these agreements, for instance, Indian companies have been authorized to develop vaccines jointly with institutions in Canada, the US and the Netherlands; others have managed to get a laboratory certification by the College of American Pathologists (Northfield, IL, USA); some have succeeded in conducting tests for multinational companies such as Merck (USA), AstraZeneca (London) and Pfizer (USA), and a number of them have been able to work with technology from the International Center of Research for Diarrheal Disease, to develop vaccines against cholera (Frew, S. et al. (2007). 
For multinational companies such agreements are often attractive when small companies have relevant information and experience concerning the legal, bureaucratic and administrative processes of the country concerned, or when the multinational is particularly interested in entering that market, or wishes to participate in local projects or invest in markets with potential for revenues that may be considered investment projects.

In Argentina and Brazil the overall organizational structure has been strengthened with a view to encouraging coordination between academia, government and business to generate synergies both among themselves and also with other sectors, seeking to provide relevant and useful information for entrepreneurs, scientists and consumers, and facilitate contact with the representatives responsible for specific issues in the different ministries, institutions and agencies. Furthermore, according to Zylberberg, C. et al. (2012), Argentina has defined strategic areas of impact for biotech developments: agribusiness, health, energy and social development, where researchers cooperate on specific projects with other prestigious institutions around the world such as the Max Planck Institute, the CERN laboratories, the Pierre Auger Observatory and SIASGE space program. Moreover, Argentina has entered into bilateral agreements with other countries seeking to further empower and leverage these projects.

Finally, mention should be made of the increased creation of biotech clusters, which concentrate the development of the sector in regions, research and development processes, knowledge, technology and efforts to access funding sources, facilitating joint projects among actors, encouraging cooperation, and facilitating access to legal advice and procedures, among others. Their existence, however, does not guarantee success for the subsequent development of the sector, to the extent that innovation activities depend not only on the physical proximity of their agents, but also on market structures, competition, the ability to convert knowledge into marketable goods and services, as well as the impact of the regulation of the balance of power among the actors involved, and a variety of additional factors (Zeller, C., 2001). Colombia is currently studying the feasibility of creating such a cluster, but so far has only conducted preliminary market studies, which suggests that its creation could be viable.

\section{Conclusions}

Main findings indicate that the market is the domain of the private sector, with a large number of small businesses whose number easily exceeds that of the multinational companies, but hold a minor market share, in a scenario where multinationals represent an oligopolistic structure and command the largest proportion of worldwide sales.

In the Colombian case, local companies dominate the market with a $73 \%$ share. However, the majority of these companies are small in size, and are the large companies and multinationals who actually control the market, generating $73 \%$ of the sector's jobs and contributing $83 \%$ of total production. One of the negative consequences of this distribution, is associated with the multinationals' modus operandi: In general, these businesses only import processed products that are locally packaged for sale to the Colombian market, and create an environment that prevents the generation of spillover effects, particularly in terms of knowledge and technology transfer, based on the management of intellectual property rights and patents, that discourage the development of the domestic biotechnology industry.

Companies' potential for development depends largely on the institutional environment within which they operate. This is because of the administrative procedures, legal requirements, need to find sources of financing and the coordination of a large number of agents, among other aspects, that are required to reach the commercialization stage. In this sense, the institutions of control established in the market where the company is located can exert a powerful influence. In Latin America, the main obstacles to progress caused by institutional and regulatory frameworks in countries such as Argentina, Brazil and Colombia are associated with government and market shortcomings arising from: the scarcity of resources; difficulties in increasing investments in infrastructure and applied research, and other financial constraints; lack of coordination between academia, the private sector and the government aimed at channeling research activities towards strategic areas and focusing research on satisfying market needs; excessive costs in terms of administrative red tape and difficulties in marketing scientific discoveries; in many cases, the absence of a specialized body in multidisciplinary areas that mitigates coordination problems and asymmetric information and that expedites cumbersome procedures for research centers and biotechnology companies.

These situations denote coordination failures and serve to increase investors' uncertainty and perception of risk, which at the same time, is prone to generate strong asymmetries of information between the scientific communities of developed and developing countries.

Upon reviewing the business strategies employed to promote the development of the biotechnology sector, it was found that each country develops its own differentiated strategy, but there are nevertheless common elements according to market conditions, obstacles and potentials of the country. Many are intended to improve coordination 
between national and international actors working on joint projects and encourage strategies that mitigate the obstacles caused by the problems described above, as is the case of the increased creation of biotech clusters, which concentrate the development of the sector in regions, research and development processes, knowledge, technology and efforts to access funding sources, facilitating joint projects among actors, encouraging cooperation, and facilitating access to legal advice and procedures, among others. It is important to highlight that the existence of such cluster does not guarantee success for the subsequent development of the sector.

\section{References}

Castellanos, O., Carrillo, A., Castro, F., \& Jiménez, C. (2011). Análisis conceptual y metodológico de la innovación tecnológica. Caso: empresas representativas del sector biotecnológico. Revista Ingeniería y Competitividad, $4(1), 55-68$.

Colciencias. (2008). La Biotecnología, motor de desarrollo para la Colombia de 2015. Grupo Biogestión de la Universidad Nacional de Colombia and CorpoGen, Bogotá, D.C., Colombia.

Defrancesco, E., \& Runge, F. (2006). Exclusion, Inclusion, and Enclosure: historical commons, and modern intellectual property. World Development, 10(34), 1713-1727.

Foros Semana. (2011). Memorias del Foro en Biotecnología y Bionegocios, Foros Semana, Bogotá.

Frew, S., Rezaie, R., Sammut, S., Ray, M., Daar, A., \& Singer, P. (2007). India's health biotech sector at a crossroads. Nature Biotechnology, 25(4), 403-418. http://dx.doi.org/10.1038/nbt0407-403

González, C., Villa, J., \& Velasco, R. (2007). Biotecnología: desde el punto de vista de los negocios. Retrieved June 8, 2011, from http://www.unicauca.edu.co/biotecnologia/ediciones/vol5/4Vol5.pdf

González, J. (2011). Herramientas de Financiación para Proyectos que involucren Bio-Diversidad de Cosméticos y Productos de Aseo. Universidad Externado de Colombia, Faculty of Finance, Government and International Relations. $\quad$ Retrieved July 9, from http://www.andi.com.co/Archivos/file/Cosmeticos/Clase\%20Mundial/BOLETIN10/PrptaUExternado.pdf

Innpulsa Colombia. (2013). - Programa de Transformación Productiva [PTP]. Estudio sobre el potencial de la industria de biotecnología en el país. Retrieved July 14, 2013, from https://www.ptp.com.co/documentos/Estudio\%20Potencial\%20de\%20las\%20Industria\%20de\%20Biotecnologia \%20en\%20el\%20Pais\%20Parte\%20C.pdf

Juma, C., \& Honca, D. (2002). Biotechnology and the precautionary principle. International Journal of Biotechnology, 4(1), 1-3. http://dx.doi.org/10.1504/IJBT.2002.000175

OC\&T. (2012) Indicadores de Ciencia y Tecnología Colombia 2010. Retrieved July 29, 2011, from http://ocyt.org.co/informes_indicadores/Indicadores_OCyT_2012/html/index.html

OCDE - Festel Capital. (2010). Industry Structure and Business Models for Industrial Biotechnology Research Methodology and Results for Discussion. OECD workshop on the Outlook on Industrial Biotechnology, Vienna, January 14, 2010.

Pearse, N. (2007). The Role of Experience in the Creation of Intellectual Capital. In Proceedings of the 4th International Conference on Intellectual Capital, Knowledge Management and Organizational Learning, p. 329. Academic Conferences Limited.

Pinilla, E. (2004). Herramientas para la competitividad a partir del uso de la biotecnología. Economía y Desarrollo, 3(2). Retrieved June 15, 2011, from http://www.fuac.edu.co/revista/II/II/seis.pdf

Zeller, C. (2001). Clustering biotech: A recipe for success? Spatial patterns of growth of biotechnology in Munich, Rhineland and Hamburg. Small Business Economics, 17(1-2), 123-141. http://dx.doi.org/10.1023/A:1011182624329

Zylberberg, C., Oner, A., \& Zylberberg, E. (2012). Biotechnology in Argentina: Development and Resources. Journal of Commercial Biotechnology, 18(3). http://dx.doi.org/10.5912/jcb528

Zylberberg, C., Oner, A., \& Zylberberg, E. (2012). Biotechnology in Brazil: An Industry Overview. Journal of Commercial Biotechnology, 18(4). http://dx.doi.org/10.5912/jcb54 